\title{
Design Research and Ambiguity
}

\author{
David Philip Green ${ }^{a^{*}}$, Joseph Lindleya \\ a Design Research Works, ImaginationLancaster, Lancaster University, United Kingdom \\ *Corresponding author e-mail: d.p.green@lancaster.ac.uk
}

\begin{abstract}
:
Design Research is powerful, promising and increasingly popular, but it is also ambiguous, broad, and contested. In this paper we draw upon interviews with leading Design Researchers and argue that some facets of this ambiguity hamper Design Research's maturation. This limits the effectiveness of Design to respond to the 21st century's entwined and complex problems. We argue that by understanding why this ambiguity exists and, where possible, attenuating its effects, the field will be galvanised and its ability to impact the world amplified. This work establishes that we may benefit from being clearer about what we mean when we talk about Design Research and explores some strategies for achieving this.
\end{abstract}

Keywords: design research; ambiguity; ontology; theory; ethnomethodology

\section{Introduction}

What we now refer to as 'Design Research' has roots in the Design Science movement of the 1960s (cf. Simon, 1969). While attempts to 'scientise' Design found some success, thinking evolved quickly and Design's suitability to unpack so-called "wicked problems" (cf. Buchanan, 1992) and to respond to "uncertainty, instability, uniqueness, and value conflict" paved the way for a distinct Design Research philosophy (Schön, 1983). Modern Design Research perspectives recognise that whilst Design is "messy and complex", this does not have to compromise rigour (Rodgers and Yee, 2016). Cross coined the term "designerly" (2011) to describe an epistemology which "has its own appropriate culture" but which does "not completely disregard other cultures" (Rodgers and Yee, 2016). On this foundation Design Research has flourished in the early part of this century, providing the methods and ideology to deliver diverse, interdisciplinary, world-class research (Cooper et al., 2018).

Design Research is one of our most powerful and versatile tools for both shaping and making sense of our rapidly changing world (Sudjic, 2009) by shedding light on "complex social, environmental and cultural challenges" (Rodgers, Francesco and Conerney, 2019) both through the "material world" but also "less tangible domains such as service, interaction and transformation design" (Cooper, 2014). From climate change, corruption and media disinformation to prevailing inequalities, injustices and health crises, Design Research can be leveraged in myriads of ways to critically explore and respond to the $21^{\text {st }}$ century's complex and interdependent challenges (Cooper et al., 2018). It can achieve this through a variety of specific practices, including (but not limited to) Critical Design, Speculative Design and Co-Design. The optimism surrounding Design Research is based on the premise that these tools are excellent facilitators, helping us to acknowledge the past, apprehend the future, and focus 
these lenses on the material concerns of the present; "Design research is a creative and transformative force that can help to shape our lives in more responsible, sustainable, meaningful, and valuable ways" (Rodgers, 2020).

Notwithstanding its growth and success, the assertion that Design Research is "pre-paradigmatic" (Gaver, 2012) remains true, with contemporary scholars grappling with means to define archetypes, typologies and taxonomies for Design Research (e.g., Pierce, 2021). The impact of this preparadigmatic character is that much effort is spent on inward discussions relating to the field's stillmaturing epistemologies, methods, and conventions (Durrant et al., 2017), meanwhile reducing the scope of the field's potential impact. The panoply of methods that Design Researchers utilise, the diverse-and usually interdisciplinary-skills which they draw upon, and the broad scope of impact, are factors that make the Design Research field one defined by its heterogeneity (Lindley and Coulton, 2020). This heterogeneity is what makes Design Research so powerful, but it also makes it difficult to break free from the pre-paradigmatic mould. The practical impacts of this are evident through the disappearance of otherwise exemplary Design Research projects into "liminal" spaces between disciplines (Green and Kirk, 2018) and a plethora of initiatives that "do not self-describe in a way that makes them discoverable as examples of Design Research" (Lindley and Coulton, 2020).

In this paper we aim to heed the advice to remain "wary of impulses towards convergence and standardisation" - factors which would arguably stifle the unique character of Design Research (Gaver, 2012)-while simultaneously responding to recent calls to "disambiguate the domain" (Lindley and Coulton, 2020). We reflect on some influential lenses on Design Research and tally those rhetorical positions with primary data collected via interviews with leading design researchers. The aspiration of the work is not to provide a dogmatic typology, but rather to better understand the nature of the questions which define Design Research's ambiguity. In doing so we offer an incremental step on the journey towards a more cohesive, stronger, and more impactful paradigm for the global Design Research community.

\section{What does 'Design Research' mean anyway?}

In Douglas Adams' Hitch Hikers Guide to the Galaxy, the answer to the 'Ultimate Question of Life the Universe and Everything' is computed as ' 42 ' - confounded by how to interpret this, it slowly dawned on the philosophers that they never really understood what the question meant, hence the answerwhilst correct-was meaningless. To avoid a similar trap when attempting to disambiguate a domain like Design Research, it is crucial that we carefully consider how to ask the question.

Design Research is an 'open compound' word, it is a concept that is made up of two existing words separated by a space. Other examples like "school bus" and "life jacket" inherit meanings from their component words, but they also have additional layers of meaning. A school bus has four wheels and a driver (like a regular bus); it contains children (like a school) but it also has unique characteristics of its own (it is often yellow, sometimes has a pop-out 'Stop' sign, and is rarely seen in the holiday season). A life jacket is worn on the torso (like a regular jacket) and is intended to protect (life), but it also has unique features (it is brightly coloured, buoyant and includes a light for attracting attention). As well as inheriting meanings and associations, compound words also relinquish meanings and associations. A life jacket is not formal attire. A school bus does not usually require a ticket. For Design Research, we should consider what meanings are inherited from the terms 'Design' and 'Research', which are not inherited, and we should also reflect on what additional meaning(s) are unique to Design Research. In each case, we may also consider under what circumstances these attributes and the relationships between them change.

Frayling's essay (1993), Research in Art \& Design sheds some light on these attributes by drawing a distinction between Research with a big ' $R$ ' and research with a little ' $r$ '. The former, Research, refers to producing new knowledge or finding out something previously unknown about the world. The latter, research, refers to the process of identifying existing information. Considering how these two types of research interact with Design, Frayling describes three archetypes Research through Design 
(producing new knowledge via a design process), Research into Design (producing new knowledge pertaining to the Design discipline), and research for Design (collating pre-existing information to contribute to a design process in some way). This typology is useful, but that utility is limited by the fact that in reality all three of these categories usually interact with one another and overlap (Lindley, 2015); put simply, when conducting a Research through Design project, it is highly likely that it will involve some research for the Design first, and the outcome will frequently constitute Research into Design.

Just as the Research element of the compound has multiple meanings, so does the Design constituent. Once again, upper and lower cases denote something here. Bamford considers lower case design to be a "cognitive activity" and uppercase Design a "social or institutional practice, or profession" (Bamford, 1990, p. 233). Resonantly Heskett's sentence, "Design is to design a design to produce a design" (2005, p. 3), uses the term in four different ways; first as a noun (the field of Design), then as a verb (the practice of design), then as another noun (a design concept), then again as a more specific noun (an instance of that concept). If we consider that most of these types of 'Design' could be active in any given discussion about Design Research, then the multiplicity of meaning confounds as much as it illuminates.

We might characterise design and research as "suitcase words" (Minsky, 2007). These are words that contain "multiple and expanding meanings across disparate contexts, [which] obfuscate as much as they clarify" (Slocum, 2018). Hence the term Design Research needs doubly unpacking as it is a compound suitcase word. A reflection of the social construction of language, Minsky notes that "Suitcase words are useful in everyday life when they help us communicate. But we won't know what each other means unless we share the same jumble of ideas" (2007, p. 110). The interviews we draw upon in the remainder of this paper are representative of the jumble of ideas that make up the Design Research community. By reflecting on these ideas, our aim is to explore the tacit ambiguities of our field and to propose new strategies to temper this complexity.

\section{Talking to People}

With such a broadly scoped issue, there are many approaches to understanding it that could be useful. For example, a theory-led approach may collate and examine the extant theories of design and Design Research and attempt a synthesis or analysis. Although theory has been cast as the Achilles' heel of design (Zimmerman, Stolterman and Forlizzi, 2010), such endeavours are not uncommon (Pierce, 2021). Another approach would be to consider examples of Design Research, distil their attributes, and use that analysis to build an improved picture of the field. However, here we encounter several interconnected challenges. There are no clear inclusion or exclusion criteria for examples of Design Research, there is no authoritative repository (although the Design Research Society has recently launched a digital library of Design Research), and as such a systematic or comparative analysis of examples is extremely challenging.

For these reasons we adopted an ethnomethodological interview approach (Crabtree, Rouncefield and Tolmie, 2012) - we aim to utilise interviews to study the methods and practices of a specific socio-cultural group (Design Researchers). In total 22 participants-all working Design Researcherswere interviewed across two cohorts. The first cohort took part in semi-structured interviews about the application of Design Research in each individual's work and was part of a research project commissioned by [anonymous] (Anonymous for review, 2020). The second cohort was interviewed as part of a 48-month project exploring the fundamentals of Design Research and included more direct questions; "What is Design?", "What is research?", "What is Design Research?" We adopt a pragmatic and interpretivist view of the data, accepting there may be multiple, sometimes incompatible, perspectives and accepting that we-the researchers-are part of the research instrument. In the following, we utilise direct quotes to allow our interviewees own voices to be most prominent. 


\section{Design Research is complex.}

That Design Research is complex is a core motivation for this paper, but it is worth noting how our participants contended with how to articulate the same point. For example, the view that Design Research is "lots of different things" (NJ) was shared among our participants. One interviewee mused that "Design Research is very far reaching [...] there are so many things it could be about maybe we should be asking the question what is Design Research, not?" (MS). An alternative view is of Design Research as a focal point around which other disciplinary perspectives can congregate; ".. basically there's a whole lot of things that come together when you put the arts and humanities together [... they] surround design, rather than necessarily being core to it" (AL). This complexity, it seems, emerges from the entanglement of the underlying concepts-e.g., "I don't know where research ends and design starts" (AJ), but yet there is a consensus that Design Research is about making sense of the world: "You go through a process of trying to understand the situation or context [... and] actually resolve it in design terms" (BG); "[You] articulate how this is located into a constellation of others things out in the world" (JV).

\section{Design Research is contested.}

Confounding the complexity are divergent perspectives on what Design Research is, what it should be and even how we can know this; "People feel that Design Research should be doing very different things and it's hard to know who's right." (RW). Clear definitions of Design Research are not forthcoming - "It's very hard to define what it is because it's a contested space" (RW), but at the same time some perspectives are quite assertive, "For me, it couldn't be further away from science!" (SW).

This discourse touches upon the intersections of art and science. While most saw combining art and science through Design Research as a promising direction, some expressed frustrations the attempts to 'scientise' Design Research noting that to do so would "suck the joy out of design" and that "Design suffers from being reduced to a rationalistic form of enquiry." (SW). Here we find echoes of the German expressionist Paul Klee, who bemoaned science concerning itself with art as "the worst state of affairs" (1964:747). Yet, similar frustrations were reported when Design Research veered too close to art. "We've been dismissed a lot as 'doing nice art pieces'... I think there's a valid critique in that." (JA)

An interesting focus of this debate is how Design Research balances art and science. While one participant notes "One way of reconciling this tension in research is to use Design Research as part of a scientific inquiry" (SP) another sees Design as an antagonist or element of contrast "There's strength in things like 'the scientific method' [...] but there is value in anarchy. You need a bit of both. Perhaps the role that design can play is to act as a contrast-an area where there's less rigidity" (RW). The tension and interplay between themes such as rigour and systematic investigation on the one hand and making, expression and creative practice on the other, underscores a shared tension at the heart of our interviewees' collective perspectives on Design Research.

\section{Design Research is interdisciplinary.}

Design Research was cast as "fundamentally interdisciplinary" (MS) and the "skill of designers is to synthesise" (SW); "There's one lesson that we took from applied art and design is to have this kind of creative synthesis of things" (NN). Interestingly, however, there does seem to be a confusion about whether it is the practice of Design Research which is an interdisciplinary craft, whether the problems which Design Research explores are interdisciplinary, or both: “...design has a really useful role for synthesising understanding, and actually trying to get round some of those problems of interdisciplinary misunderstanding by the very nature of design being a communicative tool and being able to instantiate ideas and nuance problem spaces and get people thinking because of the creative aspects of it" (DK). 


\section{Design Researchers are not an archetype.}

Perhaps unsurprisingly, whilst the identity of Design Research (the practice) remains unclear, the identity of the 'Design Researchers' (the people) remains equally unclear. In this vacuum, participants had different ways of articulating their approach, from "scavenging" methods from across disciplinary traditions (NJ) to "reinventing" approaches depending on the context (JB). Many of our participants-including several who have produced highly-regarded Design Research-do not selfidentify as Design Researchers: "I engage in some design research [... but] I wouldn' $t$ ' count myself as a designer in any normal sense" (SR); "I'm not a designer [... but] I apply design methods" (EL). Moreover, the pathways to becoming a 'Design Researcher' are not clear: "everybody kind of has their own mix of skills" (BG); "by the way we've been trained in engineering and social sciences" (JB). Design Research reflects those who practice it, but those who practice it are a diverse group. As such there is no archetype for how to define a Design Researcher, nor a clear pathway to become one.

\section{Discussion}

Through our conversations with domain experts, one uncontested point with universal agreement is the contention and ambiguity within the field. This is reflected in the diversity of the practice as well the identities of those who practice it (and arguably the forums in which we share our work too). This reflects a discipline which remains in a pre-paradigmatic state. Unpacking the individual terms Design and Research (and the relationship between them in their compound form) sheds some light on the reasons why ambiguity is an emergent property of the discipline, however such insights do little to teach us how to respond to, work around, and leverage that ambiguity. To move forward we need a mechanism to dynamically respond to the complexity, contestation, interdisciplinarity and lack of archetypes which are attributes of Design Research. And this, it seems, is key. We should not see these properties as problems but as fundamental qualities; they are, in fact, strengths.

\section{Concluding to Embrace Ambiguity}

We hope to make three contributions with this work. First, exploring the nature of the Design Research as an open compound word comprised of two suitcase words reveals that we might expect the concept to be, in some senses, undefinable, ineffable, and ambiguous. Second, the interviews with a wide range of Design Research professionals highlight the existence of concurrent but incongruent perspectives on the field. Third we offer the following provocation as a call to action for the Design Research community to embrace and work within the ambiguities we have identified.

We propose a that to empower the Design Research domain we should examine the-hitherto under-represented-corpus of existing Design Research work. We should aspire to make it accessible, available, and legible to those within and outwith the Design Research community. To achieve this aim, we must consider how we might systematically organise or archive the products of the Design Research endeavour up until this point, and going forward (i.e., a database for Design Research). Given the layers of complexity which, as we have established, are emergent properties of Design Research, such a database would require a careful consideration of the field's flexible ontology in order to broach how one might create a schematic capable of representing it meaningfully. Both as a thought experiment to galvanise perspectives within the field, but also as an actual concept to implement, we posit that an accessible repository for Design Research would be an apt and profound step towards a position where Design Researchers can legitimately argue the field is 'post pre-paradigmatic' whilst accepting that its inherent ambiguity is a key strength.

There are precious few Safe Harbours in the turbulence of the $21^{\text {st }}$ century, but Design Research is one such harbour for creative, exploratory, and interdisciplinary research. To preserve this sanctuary, we should ensure that we continue to explore, but also embrace, the inherent ambiguity of our field. 


\section{References}

Bamford, G. (1990) 'Design, science and conceptual analysis', in Proceedings of the joint ANZASCA / ADTRA conference, Sydney.

Buchanan, R. (1992) 'Wicked Problems in Design Thinking', Design Issues, 8(2), pp. 5-21.

Cooper, R. (2014) 'Design Research, Exploring the Space, Moving from One Era to Another', The Design Journal, 17(2), pp. 165-168. doi: 10.2752/175630614X13915240575906.

Cooper, R. et al. (2018) 'ImaginationLancaster: Open-Ended, Anti-Disciplinary, Diverse', She Ji: The Journal of Design, Economics, and Innovation, 4(4), pp. 307-341. doi: 10.1016/j.sheji.2018.11.001. Crabtree, A., Rouncefield, M. and Tolmie, P. (2012) Doing Design Ethnography. London: SpringerVerlag.

Cross, N. (2011) Design Thinking: Understanding How Designers Think And Work. Bloomsbury. Durrant, A. C. et al. (2017) 'Research Through Design: Twenty-First Century Makers and Materialities', Design Issues, 33(3), pp. 3-10. doi: 10.1162/DESI_a_00447. Frayling, C. (1993) 'Research in Art and Design', Royal College of Art Research Papers, 1(1), pp. 1-9. Gaver, W. (2012) 'What should we expect from research through design?', in Proceedings of the 2012 ACM annual conference on Human Factors in Computing Systems - CHI '12. New York, New York, USA: ACM Press, pp. 937-946. doi: 10.1145/2207676.2208538.

Green, D. and Kirk, D. (2018) 'Open Design, Inclusivity and the Intersections of Making', in Proceedings of the 2018 Designing Interactive Systems Conference. New York, NY, USA: ACM, pp. 173-186. doi: 10.1145/3196709.3196718.

Heskett, J. (2005) Design: A very short introduction. Oxford University Press.

Lindley, J. (2015) 'A pragmatics framework for design fiction', in Proceedings of the European Academy of Design Conference.

Lindley, J. and Coulton, P. (2020) AHRC Design Fellows Challenges of the Future: Al \& Data.

Minsky, M. (2007) The emotion machine: Commonsense thinking, artificial intelligence, and the future of the human mind. Simon and Schuster.

Pierce, J. (2021) 'In Tension with Progression: Grasping the Frictional Tendencies of Speculative, Critical, and other Alternative Designs', in Proceedings of the $2021 \mathrm{CHI}$ Conference on Human Factors in Computing Systems. New York, NY, USA: ACM, pp. 1-19. doi: 10.1145/3411764.3445406.

Rodgers, P. (2020) AHRC Design Leadership Fellowship Final Report.

Rodgers, P. A. and Yee, J. S. R. (2016) 'Design Research is Alive and Kicking', in Design Research Society Conference. doi: 10.21606/drs.2016.23.

Rodgers, P., Francesco, M. and Conerney, L. (2019) 'The Evolving Landscape of Design Research in the UK', in Proceedings of the Interactional Association of Societies of Design Research Conference 2019. Schön, D. (1983) The Reflective Practitioner: How Professionals Think In Action. Basic Books. Simon, H. A. (1969) The sciences of the artificial. The MIT Press.

Sudjic, D. (2009) The Language of Things. Penguin.

Zimmerman, J., Stolterman, E. and Forlizzi, J. (2010) 'An Analysis and Critique of Research through Design : towards a formalization of a research approach', in Proceedings of DIS 2010.

Author Bios:

David Philip Green is a designer, documentary-maker and researcher with an interdisciplinary background spanning media, arts, design and computing. (http://dpgreen.co.uk) He is currently a postdoctoral researcher at Design Research Works, Lancaster University.

Joseph Lindley currently leads Design Research Works (cf. https://designresearch.works/) which is a 4-year Fellowship project dedicated to gathering evidence about and promoting the value of Design Research. 
Acknowledgements: We thank the reviewers of this paper and the EAD conference chairs, particularly those in charge of the 'Cultivating Sustainability' and 'Reflection and Reorganisation' tracks, who united to find a home for this paper, which rather awkwardly sits somewhere between the two. Funded by UK Research and Innovation (grant reference MR/T019220/1).

\section{Appendix 1 - Interviewees.}

\begin{tabular}{|c|c|c|c|c|}
\hline & & & [1] & [2] \\
\hline Alter, Hayley & $\mathrm{HA}$ & Lancaster University & & $\mathrm{x}$ \\
\hline Auger, James & JA & Auger Loizeau / Université Paris-Saclay & $\mathrm{x}$ & \\
\hline Bleecker, Julian i & $J B$ & Near Future Laboratory & $\mathrm{x}$ & \\
\hline Boucher, Andy ii & $A B$ & Goldsmiths & $\mathrm{x}$ & \\
\hline Gaver, Bill ii & BG & Goldsmiths & $\mathrm{x}$ & \\
\hline Hall, Dame Wendy & WH & Web Science Trust & $\mathrm{x}$ & \\
\hline Jacobs, Naomi & NJ & Lancaster University & & $\mathrm{x}$ \\
\hline Jain, Anab & AJ & Superflux / University of Applied Arts, Vienna & $\mathrm{x}$ & \\
\hline Kirk, Dave & DK & Newcastle University & $x$ & \\
\hline Kirman, Ben & $\mathrm{BK}$ & University of York & $x$ & \\
\hline Light, Ann & $A L$ & University of Sussex & $x$ & \\
\hline Luger, Ewa iii & EL & University of Edinburgh & $x$ & \\
\hline Nova, Nicolas i & NN & Near Future Laboratory & $x$ & \\
\hline Pollastri, Serena & SP & Lancaster University & & $x$ \\
\hline Powell, Alison & AP & London School of Economics & $x$ & \\
\hline Reeves, Stuart & SR & Nottingham University & $x$ & \\
\hline Speed, Chris iii & CS & University of Edinburgh & $x$ & \\
\hline Sturdee, Miriam & MS & Lancaster University & & $\mathrm{x}$ \\
\hline Vallor, Shannon & SV & University of Edinburgh & $x$ & \\
\hline Vines, John & $\mathrm{JV}$ & Northumbria University & $\mathrm{x}$ & \\
\hline Walker, Stuart & SW & Lancaster University & & $x$ \\
\hline Whitham, Roger & RW & Lancaster University & & $x$ \\
\hline
\end{tabular}

[1] First interview cohort (interviewed 2020)

[2] Second interview cohort (interviewed 2021)

i / ii / iii Participants interviewed together. 